\title{
INVESTIGACIÓN
}

Recibido: 21/11/2019 --- Aceptado: 20/02/2020 --- Publicado: 15/12/2020

\section{EL ROL DEL AUDIOVISUAL PRODUCTION RESEARCHER EN EL TRATAMIENTO DE LA DOCUMENTACIÓN AUDIOVISUAL}

\author{
The role of audiovisual production researcher in the treatment of audiovisual \\ documentation
}

(D) 8duardo Alejandro Hernández Alfonso": Universidad Central "Marta Abreu" de Las Villas. Cuba.

ealejandro@uclv.cu.

8) Luis Ernesto Paz Enrique: Universidad Central "Marta Abreu" de Las Villas. Cuba.

luisernestope@uclv.cu.

Rachel Milagros Pérez Cabrera: Universidad de Cienfuegos "Carlos Rafael Rodríguez". Cuba.

rpcabrera@nauta.cu.

\section{RESUMEN}

Los roles en el tratamiento de la documentación audiovisual tienen una gran variedad de denominaciones. Entre las más comunes se encuentran Production Researcher, TV Researcher, Film Researcher, Programme Researcher y Video Librarian. Aunque las denominaciones varían, las funciones se limitan al procesamiento, almacenamiento, custodia y difusión de las colecciones audiovisuales. La definición de un nuevo rol que además de realizar las actividades de los anteriores, participe en el proceso de producción audiovisual, permitirá superar las limitaciones que presenta el documentalista audiovisual. Se plantean como objetivos del estudio: 1) Identificar los roles tradicionales del profesional de la información en el tratamiento de la documentación audiovisual, 2) Fundamentar el Audiovisual Production Researcher como un nuevo rol en el tratamiento de la documentación audiovisual. El presente estudio clasifica como descriptivo con aporte teórico. Para la obtención de resultados se emplearon los métodos analíticosintético, histórico-lógico, inductivo-deductivo, sistémico-estructural y el análisis documental clásico. Se define el rol del Audiovisual Production Researcher como un profesional con un papel activo en la elaboración de los audiovisuales. Participa en la

\footnotetext{
${ }^{1}$ Eduardo Alejandro Hernández Alfonso: licenciado en Comunicación Social. Doctorando de Ciencias
} Sociológicas. Profesor de la Universidad Central “Marta Abreu” de Las Villas. 
Hernández Alfonso, E. A., Paz Enrique, L. E. y Pérez Cabrera, R. M.

El rol del audiovisual production researcher en el tratamiento de la documentación audiovisual

concepción de la idea (fase de planificación), elaboración del guion y emplea metadatos o descriptores en la concepción de la idea; garantizado mayor organización para el posterior trabajo de realización y procesamiento.

PALABRAS CLAVE: Audiovisual Production Researcher - Tratamiento audiovisual - Documentación audiovisual - Producción audiovisual - Procesamiento de la información audiovisual

\section{ABSTRACT}

The roles in the treatment of audiovisual documentation have a great variety of denominations. Among the most common are Production Researcher, TV Researcher, Film Researcher, Program Researcher and Video Librarian. Although the names vary, the functions are limited to the processing, storage, custody and dissemination of audiovisual collections. The definition of a new role that in addition to carrying out the activities of the previous ones, participates in the audiovisual production process, will overcome the limitations presented by the audiovisual documentary filmmaker. The objectives of the study were: 1) identify the traditional roles of the information professional in the treatment of audiovisual documentation, 2) to base the Audiovisual Production Researcher as a new role in the treatment of audiovisual documentation. The present study classifies as descriptive with theoretical contribution. The analytical-synthetic, historical-logical, inductive-deductive, systemic-structural and classical documentary analysis methods were used to obtain results. The role of Audiovisual Production Researcher is defined as a professional with an active role in the development of audiovisuals. Participates in the conception of the idea (planning phase), writing the script and uses metadata or descriptors in the conception of the idea; Guaranteed greater organization for the subsequent work of realization and processing.

KEY WORDS: Audiovisual Researcher Production - Audiovisual processing Audiovisual documentation - Audiovisual production - Processing of audiovisual information

\section{O PAPEL DO AUDIOVISUAL PRODUCTION RESEARCHER NO TRATAMENTO DA DOCUMENTAÇAO AUDIOVISUAL}

\section{RESUMEN}

Os papéis no tratamento da documentação audiovisual tem uma grande variedade de denominações. Entre Os mais comuns se encontram Production Researcher, TV Researcher, Film Researcher, Programme Researcher e Video Librarian. Apesar de que as denominações variam, as funções se limitam ao processamento, armazenamento, custódia e difusão das coleções audiovisuais. A definição de um novo papel que além de executar as atividades dos anteriores, participe no processo de produção audiovisual, permitirá superar as limitações que apresenta o 
Hernández Alfonso, E. A., Paz Enrique, L. E. y Pérez Cabrera, R. M.

El rol del audiovisual production researcher en el tratamiento de la documentación audiovisual

documentarista audiovisual. São definidos como objetivos do estudo: 1) Identificar os papéis tradicionais do profissional da informação no tratamento da documentação audiovisual, 2) Sustentar o Audiovisual Production Researcher como um novo papel no tratamento da documentação audiovisual. O presente estudo se classifica como descritivo com aporte teórico. Para a obtenção de resultados usaram-se os métodos analítico-sintético, histórico-lógico, indutivo-dedutivo, sistêmico-estrutural e a análise documental clássica. Se define o papel Audiovisual Production Researcher como um profissional com um papel ativo na elaboração dos audiovisuais. Participa na concepção da ideia (fase de planejamento), elaboração do roteiro e emprega metadados ou descritores na concepção da ideia; garantindo maior organização para o posterior trabalho de realização e processamento.

PALAVRAS CHAVE: Audiovisual Production Researcher - Tratamento audiovisual - Documentação audiovisual - Produção audiovisual - Processamento da informação audiovisual.

\section{Como citar el artículo:}

Hernández Alfonso, E. A., Paz Enrique, L. E. y Pérez Cabrera, R. M. (2020). El rol del audiovisual production researcher en el tratamiento de la documentación audiovisual. [The role of audiovisual production researcher in the treatment of audiovisual documentation].Vivat Academia. Revista de Comunicación, 153, 55-71. doi: https://doi.org/10.15178/va.2020.153.55-71 Recuperado de http://www.vivatacademia.net/index.php/vivat/article/view/1208

\section{INTRODUCCIÓN}

La documentación audiovisual puede definirse como "la disciplina que tiene por objeto el estudio del proceso de comunicación de las fuentes audiovisuales para la obtención de nuevo conocimiento aplicado a la investigación y el trabajo audiovisual" (Cebrián, 1995, p. 32). Para Cuadra (2007) el documento audiovisual es un conjunto de imágenes y de sonidos que las acompañan (perceptible mediante tecnología interpuesta). Independientemente a los aspectos técnicos formales que devienen en el audiovisual, producen la sensación de imágenes en movimiento perceptibles.

Los documentos audiovisuales tienen características propias que no poseen otros documentos. Lo anterior sumado a que su análisis, procesamiento y conservación también difiere de otras tipologías documentales y merece una observación detallada de sus cualidades. Los profesores Alfonso López Yepes, Rodrigo Sánchez Jiménez y José Ramón Pérez Agüera señalan al respecto (2003):

“... Los documentos audiovisuales, entendidos como aquel soporte material perdurable en el que, por medio de los códigos visual y sonoro, se transmite intencionadamente una información de la actividad del

Vivat Academia. Revista de Comunicación. 15 diciembre 2020 /15 marzo 2021, nº 153, 55-71 
Hernández Alfonso, E. A., Paz Enrique, L. E. y Pérez Cabrera, R. M.

El rol del audiovisual production researcher en el tratamiento de la documentación audiovisual

hombre, con el fin de que se difunda y perdure en la memoria de la humanidad..." (p. 40).

Como se ha indicado anteriormente las características del documento audiovisual son diferentes a otras fuentes. "Mientras que el documento textual es simple, uniforme, transparente, autónomo, claro y estable, el documento audiovisual se caracteriza por ser múltiple, multiforme, incompatible, dependiente, opaco y ambiguo" (Pérez, 1996, p. 122). Para el análisis de la cita anterior se utiliza el aporte de Hidalgo (1999) donde desarrolla las siguientes cuatro características de los documentos audiovisuales:

- Dualidad: los documentos audiovisuales contienen sonido e imagen, por lo que se podría desdoblar el documento audiovisual en dos, uno sonoro y otro visual, que aporta cada uno su información y que en ciertas ocasiones pueden llegar a presentarse físicamente por separado, como puede ser en el caso del cine de doble banda.

- Ambigüedad: la información sonora y la visual en ocasiones son complementarias, por lo que no existen referentes y la información se puede entender de varias maneras o admitir varias interpretaciones.

- Opacidad: su contenido no es legible o accesible de forma directa. Es necesaria la utilización de aparatos de lectura (moviolas, magnetoscopios y monitores). Son documentos dependientes de los medios técnicos.

- Incompatibilidad: ya que están grabados en múltiples soportes y diversos formatos, por lo que es necesario contar con el aparato de lectura indicado en cada uno de los casos.

Desde la primera aparición del primer grabador de cintas en 1956, la industria ha mantenido una lucha constante por los formatos. Lo anterior ha favorecido el desarrollo de esta tipología en archivos de diversos soportes cuyo contenido sólo se puede visualizar en reproductores obsoletos. En muchos casos no existen piezas de recambio por lo que están obligados a la migración o repicado continuo de esos soportes.

Autores como Eugenio López de Quintana (2014), Caldera y Arranz (2013) han realizado una clasificación de los documentos audiovisuales en televisión. Destacan López y otros (2003) que atiende a diferentes criterios:

- Según el tipo de soporte: desde soportes químicos hasta soportes magnéticos.

- Según el origen de la información: documentos cinematográficos, televisivos, de elaboración independiente.

- Según el sistema de transmisión empleado: fusión de la imagen con el sonido, aunque puede darse prioridad en ocasiones a uno de estos dos códigos, el visual o el sonoro. 
Hernández Alfonso, E. A., Paz Enrique, L. E. y Pérez Cabrera, R. M.

El rol del audiovisual production researcher en el tratamiento de la documentación audiovisual

- Según el tipo de mensaje: 1) por contenidos temáticos: mensajes de ficción (películas, series, dibujos animados) y mensajes de no ficción (como informativos, reportajes o documentales).

- Según su extensión o profundidad de tratamiento de contenidos: en películas se distingue el cortometraje, mediometraje y largometraje. En el caso de los documentos videográficos informativos, se diferencian entre informativo diario o semanal.

- Según su periodicidad: no sujetos a periodicidad fija (como las películas) y documentos periódicos (diarios, semanales, quincenales, mensuales $\mathrm{o}$ anuales).

- Según su difusión o accesibilidad: ámbito geográfico de producción local, regional, nacional o internacional, localización institucional documentos de producción propia o producción ajena, pertenencia organizacional, instituciones privadas, de más difícil accesibilidad, u organismos públicos, de más fácil acceso.

La documentación audiovisual en televisión tiene además un doble valor, tal y como han señalado Caldera y Nuño (2002):

- Valor de explotación: los servicios de documentación audiovisual tienen su razón de ser en dar a conocer la información a sus usuarios. Por ello la reutilización es el principal recurso de la puesta en marcha de estos centros. Al usar imágenes ya grabadas para anteriores programas o informaciones que se conservan en el archivo no es necesario enviar un equipo para grabar nuevo material, lo que supone un ahorro económico para la empresa. Entre los modos de reutilización de material de archivo se distingue la reutilización de extractos en distintas producciones, la reemisión y la venta, por lo que el centro de documentación audiovisual tiene también un valor comercial al poner a la venta sus fondos.

- Valor patrimonial: los documentos audiovisuales conservados en una televisión pueden tener un valor patrimonial para historiadores, sociólogos o comunicólogos a corto, medio y largo plazo, lo que condicionará su conservación, así como su política de selección. En ese valor patrimonial son fundamentales aquellos fondos audiovisuales conservados desde hace 10 años o más, creándose así una memoria patrimonial audiovisual.

A partir de las consideraciones anteriores se puede establecer que un documento audiovisual correctamente procesado, influye en el ahorro de medios, tiempo y gastos de producción de manera general. El procesamiento adecuado permite reutilizar imágenes sin la necesidad de grabar nuevas. Lo anterior está directamente relacionado con su valor de explotación. Este tipo de documentos, pueden tener valor patrimonial, al reflejar en sus emisiones personalidades, lugares, hechos históricos, culturales, sociales, entre otros de trascendencia para el futuro. 
Hernández Alfonso, E. A., Paz Enrique, L. E. y Pérez Cabrera, R. M.

El rol del audiovisual production researcher en el tratamiento de la documentación audiovisual

Los documentos audiovisuales en televisión pueden ser clasificados teniendo en cuenta su origen o su grado de elaboración. Con respecto a su origen, Hidalgo (2003) establece:

- Documentos que han sido producidos o generados por la propia empresa.

- Documentos de producción ajena, adquiridos por la empresa en el exterior, ya sea para la producción y emisión.

Teniendo en cuenta su grado de elaboración Caldera (2003) diferencia:

- Documentos audiovisuales primarios: aquellos que no han sufrido ningún tipo de modificación para su conservación. Se trata de brutos (imágenes grabadas por los reporteros, sin editar), y los programas en directo.

- Documentos audiovisuales secundarios: aquellos que han sufrido diversas modificaciones al añadirles locución, montaje, postproducción, etc. En este sentido, cualquier producto en informativos sería un documento secundario al ser resultado de anteriores documentos primarios.

- Documentos audiovisuales terciarios: se trata de los denominados "montaje de archivo". Se elaboran a partir de documentos secundarios y en ello la información se extrae de otros productos ya emitidos o conservados en el archivo.

Se señalan, además, las funciones que cumple la documentación audiovisual en televisión. A criterio de Suing (2011) estas funciones pueden ser:

- una función propiamente informativa, cuando contextualiza la información y los documentos aportan su valor testimonial y evocador;

- una función completiva, en noticias que tienen vacíos informativos;

- una función ilustrativa o simbólica, para ilustrar temas abstractos o que carecen de imágenes propias, como para apoyar el texto sonoro o la información gráfica.

El profesional de la información o documentalista se torna actualmente imprescindible en cualquiera de sus esferas de actuación (archivos administrativos e históricos, consultorías de cualquier índole, empresas, editoriales, bibliotecas en su más amplia tipología, centros de información y/o documentación). El desarrollo del hipertexto y las Tecnologías de la Información y las Comunicaciones han favorecido que el accionar del profesional de la información (documentalista) se expanda y diversifique. Para Cano (2015) el especialista en Ciencias de la Información se puede contemplar desde siete puntos de vista:

- Bibliotecario y archivero o information retriever: trabaja con una colección de documentos sobre la que ha construido un sistema de recuperación. 
Hernández Alfonso, E. A., Paz Enrique, L. E. y Pérez Cabrera, R. M.

El rol del audiovisual production researcher en el tratamiento de la documentación audiovisual

- Constructor de sitios web o site builder: como experto en la clasificación de contenidos el documentalista resuelve los aspectos de la organización de las páginas y su jerarquía. El proceso que desarrolla es denominado arquitectura de información.

- Gestor de información o information manager: el documentalista trabajará con la base de datos para reestructurarla de una forma técnicamente óptima, natural y fácil de consultar. Es capaz de recoger toda la información necesaria.

- Técnico de inteligencia competitiva: en esta faceta el documentalista no trabaja con datos e información interna de la empresa, sino que sistematiza y mantiene un proceso para detectar sucesos externos de interés.

- Curador de contenidos o content curator $^{2}$ : esta función tiene contexto en la Web. Consiste en la recepción o búsqueda de contenidos nuevos relacionados con la temática de cada sitio, la posterior selección crítica de los mismos y la publicación.

Este último aspecto puede ser mediante enlace simple a las fuentes o a partir de contenidos propios reelaborados a partir de ellas:

- Gestor de la comunidad o community manager: es en gran medida la imagen profesional de la empresa, organización o evento. Desde el punto de vista de los usuarios o clientes, él es el representante y todo lo que publica y menciona lleva la firma de la organización. Funciona como dinamizador de respuestas en los seguidores de la empresa o marca para lograr un objetivo determinado o mantener un cierto nivel de atención.

- Analizador de datos - asistente de especialista: en esta esfera el documentalista trabaja principalmente con datos. Explora sus facetas y características en busca de relaciones significativas. Es una labor ideal para apoyar a otros especialistas (del área del marketing, estrategia, dirección, etc.) cuando éstos disponen de un conjunto de datos en bruto.

Debido al creciente desarrollo tecnológico en el sistema audiovisual, el profesional de la información en este campo ha avanzado en cuanto a la representación. A criterio de la comunidad profesional Dokumentalistas (2016) este profesional asumiría otras funciones como:

- Archiveros audiovisuales o archivist: profesionales ligados normalmente a una empresa de producción audiovisual, entre cuyas tareas principales son el análisis del material: la descripción de la imagen misma o del programa, reportaje, etc., en su conjunto para su posterior recuperación al servicio de la empresa para la que trabajan.

\footnotetext{
2 El autor citado también denomina esta faceta del profesional de la información o documentalista como comisario de contenidos, o intermediario de contenidos
} 
Hernández Alfonso, E. A., Paz Enrique, L. E. y Pérez Cabrera, R. M.

El rol del audiovisual production researcher en el tratamiento de la documentación audiovisual

- Bibliotecario audiovisual o video librarian: gestiona los fondos audiovisuales de una biblioteca con múltiples soportes no necesariamente vinculados de forma exclusiva al mundo de la imagen.

- Especialista en recuperación de la información o researcher: el especialista en recuperación de la información se encargaría de buscar documentación en cualquier soporte documental para un periodista, realizador, director de cine, responsables de una producción audiovisual por lo general, sea cine, publicidad o televisión.

Es preciso destacar que el profesional de la información debe estar en constante aprendizaje y superación. Los autores Muñoz, Meana, y Sáez (2014) consideran que el documentalista audiovisual es el profesional que ha experimentado una mayor transformación, pasando a ser pieza clave en el sistema. Caldera y Freire (2016) consideran que "el documentalista está cambiando su papel de intermediario directo, para serlo como gestor del sistema. Su función de trabajo no está en peligro, sino en constante mutación". La profesión del documentalista en el sector audiovisual tiene grandes perspectivas. La era digital supone un protagonismo del profesional en ese entorno.

El profesional de la información, en cuanto al audiovisual cuenta con un alto grado de especialización. Debe llevar a cabo tareas que logren asegurar los nuevos retos del procesamiento y adquirir conocimientos en cuanto a equipos y herramientas necesarias para el desarrollo óptimo de su rol como profesional. A criterio de Hernández, Martínez, y Paz (2017) el videotecario debe actualizarse constantemente en lo referente a las nuevas técnicas de hacer televisión. Debe comprender los códigos televisivos en función de detectar, localizar y recuperar el contenido que va a formar parte del archivo digital del canal de televisión. Además de decidir el tratamiento documental que requiere cada tipo de programa.

Debe valerse de herramientas que le ayuden a representar los contenidos audiovisuales, de tal forma que permita el acceso y recuperación por parte de los usuarios (periodistas, realizadores, audiencias). Los autores Muñoz y otros (2014) consideran que el documentalista audiovisual es el profesional que ha experimentado una mayor transformación, convirtiéndose en pieza clave en el sistema. Muchas televisoras prefieren su inserción desde el principio del proceso de producción, considerando que el tratamiento documental se encuentra ahora en el inicio y no sólo al final de la cadena.

La asignación de roles en el tratamiento de la documentación audiovisual varía según las instituciones donde se encuentre el profesional encargado de esta labor. A partir de lo anterior se encuentran denominaciones de roles como Production Researcher, TV Researcher, Film Researcher, Programme Researcher y Video Librarian (videotecario). Aunque las denominaciones varían, las funciones son esencialmente las mismas: procesar, almacenar y custodiar las colecciones de documentos audiovisuales tanto en formato digital como impreso. 
Hernández Alfonso, E. A., Paz Enrique, L. E. y Pérez Cabrera, R. M.

El rol del audiovisual production researcher en el tratamiento de la documentación audiovisual

Además de las funciones mencionada con anterioridad también deben buscar y recuperar información audiovisual para satisfacer las necesidades de usuarios y clientes. La definición de un nuevo rol que además de realizar las actividades de los anteriores, participe en el proceso de producción audiovisual, permitirá superar las limitaciones que presenta el documentalista en el ámbito audiovisual.

\section{OBJETIVOS}

Identificar los roles tradicionales del profesional de la información en el tratamiento de la documentación audiovisual.

Fundamentar el Audiovisual Production Researcher como un nuevo rol en el tratamiento de la documentación audiovisual.

\section{METODOLOGÍA}

El estudio que se presenta clasifica como descriptivo con aporte teórico. Se enfoca en establecer los fundamentos del Audiovisual Production Researcher como un nuevo rol profesional en el tratamiento de la documentación audiovisual. Se emplean métodos en los niveles teóricos:

Histórico-lógico: se analiza la evolución de los roles Production Researcher, TV Researcher, Film Researcher, Programme Researcher y Video Librarian a partir de la aparición de los diferentes formatos audiovisuales.

Analítico-sintético: se examinaron las conceptualizaciones aportadas para los roles Production Researcher, TV Researcher, Film Researcher, Programme Researcher y Video Librarian, diseñadas e implementadas en diversos contextos con el objetivo de hacer inferencias. A partir de las concepciones de los roles mencionado, se analizan los aspectos que deben estar presentes en la fundamentación del rol Audiovisual Production Researcher.

Inductivo deductivo: asistió al análisis e interpretación de los datos obtenidos, lo que permitió arribar a inferencias relativas al objeto de la investigación, especialmente en los roles existentes en el tratamiento de la documentación audiovisual.

sistémico-estructural: permitió la estructuración lógica de los contenidos, se jerarquizaron criterios teniendo en cuenta la generalidad de los conceptos y se organizó la información presentada partiendo de lo general a lo particular.

En el nivel empírico se emplea el análisis documental clásico a partir de la consulta de fuentes y bases de datos especializadas sobre las temáticas que se abordan. La técnica empleada fue la revisión de documentos. Esta facilita la 
Hernández Alfonso, E. A., Paz Enrique, L. E. y Pérez Cabrera, R. M.

El rol del audiovisual production researcher en el tratamiento de la documentación audiovisual

localización de referentes teóricos sobre la temática en cuestión a partir de un exhaustivo análisis documental.

\section{RESULTADOS}

Los investigadores o researchers trabajan en todos los géneros de la producción televisiva: cine, noticiarios, deportes, temas de actualidad, documentales y programas de hechos, infantiles, comedias de situación, telenovelas o series dramáticas y dramas únicos. Son muchas las definiciones empleadas para categorizar a los especialistas que se desempeñan en videotecas, mediatecas, cinematecas o con productoras independientes de audiovisuales. Algunos de ellos son: el TV Researcher, Programme Researcher, Production Researcher, Video Librarian, Film Researcher (Cuadra, 2013), entre otros.

La existencia de tantos conceptos o roles no representa una diferencia significativa entre ellos. Por otra parte, muchas veces las diferencias entre los conceptos es la limitación de las funciones del especialista a un formato específico, como es el cine o la televisión. Son diferentes las nacionalidades de los investigadores que han teorizado sobre las funciones que ejercen los especialistas en documentación audiovisual y por tanto diferentes son sus terminologías.

Los investigadores de origen español Bailac y Catalá (2003) señalan que el documentalista audiovisual es una especialización vinculada. Sobre el criterio anterior Caldera (2015) establece que la especialidad surge en el ámbito de la imagen en movimiento, el cine y la televisión; cuya denominación en el mundo anglosajón es Archivist, Video Librarian y Researcher. El autor destaca tres subespecialidades en dicha materia:

- documentalista o archivero audiovisual, que sería aquél que realiza el análisis de la información audiovisual

- el bibliotecario o documentalista, que gestionaría la información audiovisual de instituciones no especialmente vinculadas a los medios de comunicación

- y el especialista en recuperación de información de lo audiovisual para empresas audiovisuales, en la mayor parte de los casos, y para la generación de nuevos productos

Existen también perfiles como los Media o Multimedia Asset Management (MAM) para plataformas analógicas y su evolución en los Digital Asset Management (DAM). Estos especialistas tienen labores más flexibles ya que están estrechamente relacionadas con los cambios en los medios audiovisuales. Básicamente su labor conlleva inclusión de metadatos, gestión de la información, búsqueda y recuperación en los sistemas y, muy especialmente, el almacenamiento de datos digitales.

Mediante el desarrollo del presente estudio se ha identificado ambigüedad en la descripción de los roles relacionados con la documentación audiovisual. En la 
Hernández Alfonso, E. A., Paz Enrique, L. E. y Pérez Cabrera, R. M.

El rol del audiovisual production researcher en el tratamiento de la documentación audiovisual

literatura científica existente predomina escasez de referentes publicados sobre cada uno de los roles y sus funciones específicas. Los principales escenarios para encontrar la descripción de las funciones de estos roles son en planes de formación profesional o páginas web empleadoras.

La presente investigación propone y teoriza sobre un nuevo rol: el Audiovisual Production Researcher. Este profesional se apropiaría de las funciones básicas del Production Resercher, Film Researcher, y el TV Researcher. El perfil requiere conocimientos, competencias, habilidades y destrezas de los especialistas de la Información y la Comunicación. Para el desarrollo de las funciones de este perfil se analiza el estudio "Production Research: el nuevo rol profesional para nuevos tiempos en la gestión de la información audiovisual” de Caldera (2015).

El autor mencionado menciona que el perfil más apropiado para asumir el nuevo rol enunciado sería el de un egresado de Ciencias de la Información (Documentación). El rol del Audiovisual Production Researcher pudiera ser realizado por un comunicador social con un entrenamiento previo en lo concerniente al procesamiento de la información audiovisual.

A partir de las pocas fuentes existentes sobre los roles y funciones de los profesionales que laboran en el ámbito de la documentación audiovisual, se describen los roles y funciones del Production Resercher, TV Researcher, y el Film Researcher. La figura del Production Researcher a decir de Caldera (2015) no está tan estandarizada y se trata de un rol mucho más activo e integrado en las labores de realización, control y producción de la información audiovisual. "Los conocimientos que debe incluir este perfil profesional se basan en conocer las diferentes tipologías de fuentes de información audiovisual: sus características físicas, estructura, producción y generación, y sus formas de acceso y uso" (Caldera y León, 2010, p. 67).

Tal profesional debe ser experto y conocedor de las colecciones audiovisuales, así como de su contenido temático y su alcance. Debe identificar las herramientas para satisfacer las necesidades de investigación en el ámbito audiovisual y detectar las diferentes necesidades que acarrea un proyecto de investigación y/o de producción audiovisual. El profesional deberá determinar las mejores fórmulas para la búsqueda de información tanto de carácter audiovisual como de carácter textual; en definitiva, ha de ser capaz de buscar la información requerida independientemente de su naturaleza (Caldera y Arranz, 2013).

El Production Researcher es un profesional con habilidades suficientes y necesarias para poder evaluar de forma oportuna la información recuperada. En un mundo donde la infoxicación ${ }^{3}$ es una realidad y por lo tanto un problema, el Production Researcher debe contar con la capacidad de discernir entre lo veraz y lo incierto. Debe

\footnotetext{
${ }^{3}$ La infoxicación es una tendencia del crecimiento desbocado de la información en la red, pues vivimos en un oasis de fuentes de información que nos puede llevar a lo que se conoce como sobrecarga informativa o information overload (Herrera, 2013).
}

Vivat Academia. Revista de Comunicación. 15 diciembre 2020 /15 marzo 2021, n 153, 55-71 
Hernández Alfonso, E. A., Paz Enrique, L. E. y Pérez Cabrera, R. M.

El rol del audiovisual production researcher en el tratamiento de la documentación audiovisual

ponderar aquello que es más útil y relevante. El especialista debe tener también las destrezas para conocer las estructuras documentales. Ser un buen usuario de los servicios de información de las diferentes entidades audiovisuales independientemente de su naturaleza.

El profesional debe tener muy claro que la gestión documental no es la misma en televisión que en productoras audiovisuales, en agencias de información que en colecciones audiovisuales públicas o privadas. El Production Researcher es un experto buscador de información. Se especializa en las fuentes de información audiovisual, fuentes que serán tanto públicas como privadas, institucionales como personales.

Otros de los conceptos que se pueden encontrar en la bibliografía publicada son el Media Researcher o Programme Researcher. Ambas profesiones, así como el Production Researcher son más generales. Sus destrezas le permiten trabajar en todos los ámbitos de la producción audiovisual: cine, televisión y producciones independientes. Sin embargo, nuevamente existen limitantes en su desempeño, pues no posee un alto grado de especialización en los procesos técnicos documentales.

El Programme Researcher por ejemplo ha de brindar apoyo al productor y al equipo de producción de un proyecto de televisión, radio, película o en línea. Puede trabajar en una variedad de programas o dentro de un área temática. El trabajo a menudo se ve como un trampolín hacia un rol de productor. Nótese entonces que es uno de los roles más completos, pero está más inclinado a la producción de programas en vivo.

El papel también puede ser conocido como:

- Especialista en imágenes en vivo o investigador de imágenes

- Asistente de transmisión o

- Productor asistente

El trabajo del Media Researcher no dista mucho del Programme Researcher: en este caso está más apegado a la producción de un proyecto en línea. El Media Researcher debe buscar los colaboradores adecuados y encontrar sus contactos. Investigar el material necesario para la producción y estar al tanto del equipo de filmación, así como del presupuesto.

El TV Researcher por otra parte trabajará investigando e ingresando información para proyectos digitales. Se enfoca únicamente en el medio televisivo. Se espera que realicen su propia investigación. Debe consultar ámbitos y sitios web de la industria diariamente, así como otras noticias y fuentes de clientes, para garantizar que el sitio cuente con la información más actualizada disponible. El candidato ideal debería tener:

- Buena capacidad de comunicación.

- La capacidad de ser proactivo y tomar iniciativa.

- Un alto grado de conocimiento sobre la industria televisiva. 
Hernández Alfonso, E. A., Paz Enrique, L. E. y Pérez Cabrera, R. M.

El rol del audiovisual production researcher en el tratamiento de la documentación audiovisual

- Conocimiento del ciclo de desarrollo de la televisión.

- Un buen ojo para el detalle.

- La capacidad de gestionar grandes cantidades de datos e información de manera oportuna y precisa.

- La capacidad de trabajar bien con un equipo, así como de forma independiente.

- Experiencia trabajando con la recolección de datos o sistemas de gestión de contenidos.

El Film Researcher es una profesión que ha ganado mucho protagonismo en los últimos años. El Film Researcher es el encargado de realizar búsquedas en fuentes documentales externas para conseguir información muchas veces muy difícil de localizar. Según la literatura científica existente "el Film Researcher, aquel que consigue la información interrogando bancos de imágenes externos a la propia institución, independientemente de su ámbito geográfico" (López, 2013).

Debe resaltarse que la figura del Film Reasearcher está más enfocado al cine y al análisis y tratamiento de material fílmico. Esta figura es necesaria principalmente para la producción cinematográfica que con frecuencia necesitan de información muy detallada y otras veces, por el contrario, muy poco definida e incluso ambigua. Las competencias que debe cubrir el rol del Film Researcher a criterio de Caldera (2015) son:

- Conocer los sistemas, los productos y los recursos necesarios para llevar a cabo el trabajo de documentación en materiales fílmicos.

- Poseer habilidades de análisis documental de fondos audiovisuales.

- Tener habilidades de búsquedas en archivos audiovisuales.

- Conocer en profundidad el proceso de documentación de un producto cinematográfico.

- Conocer y ser conscientes de la problemática de la preservación de fondos audiovisuales cinematográficos.

- Conocer la casuística de la gestión de compra de imágenes.

- Conocer y ser conscientes de los aspectos legales de la información audiovisual.

\section{DISCUSIÓN}

A diferencia de los demás roles sus habilidades solo involucran materiales fílmicos, lo que supone una limitante. El Audiovisual Production Researcher es aquel especialista cuyas competencias profesionales le permiten trabajar tanto en cine, televisión como en productoras independientes. Las habilidades de este profesional le aportan destrezas para trabajar en todo el proceso de documentación audiovisual, así como en todas las etapas del ciclo de vida de la información. 
Hernández Alfonso, E. A., Paz Enrique, L. E. y Pérez Cabrera, R. M.

El rol del audiovisual production researcher en el tratamiento de la documentación audiovisual

El Audiovisual Production Researcher se encargará de generar o desarrollar ideas de programas, basándose en su conocimiento y comprensión de los requisitos de la industria. Podrá además presentar sus hallazgos a quienes toman las decisiones en las grandes compañías televisivas. También será comprobador de hechos y escritor de "breves" para presentadores en pantalla. Pueden ser empleados por emisoras, televisoras o trabajar de forma independiente.

Los productores $\mathrm{u}$ otros responsables de la toma de decisiones pueden informar al Audiovisual Production Researcher sobre las ideas del programa. Alternativamente pueden producir ideas originales del programa para que sean consideradas por los productores, los difusores, las compañías de producción u otros con la facultad de tomar decisiones. Identifican datos relevantes, colaboradores, ubicaciones, material de archivo, entre otros. Recopilan y evalúan información de diversas fuentes y garantizan que se cumplan los requisitos legales, de cumplimiento y de copyright.

Durante las entrevistas preliminares telefónicas y / o cara a cara, evalúan la posible utilidad de los colaboradores para su inclusión en cada programa de acuerdo con su género y formato. Verifican la disponibilidad de los colaboradores y organizan su aparición dentro de los límites de tiempo y presupuesto. También se les puede solicitar que identifiquen los requisitos de ubicación de los guiones o los esquemas del programa y evalúen la idoneidad y el costo de las ubicaciones.

Se tienen en cuenta diversos factores incluida la necesidad de permisos y licencias. Identifican y seleccionan fuentes adecuadas para el archivo, imágenes fijas o materiales de audio, dentro de los límites de tiempo y costo. Deben presentar todos sus hallazgos a los encargados de tomar las decisiones. Toda información que ofrezcan a directores y productores deben presentarla de manera clara, concisa y coherente, tanto por escrito como verbalmente.

El Audiovisual Production Researcher puede contribuir al desarrollo de guiones $\mathrm{u}$ otro contenido escrito escribiendo borradores o informando a otros que escriben para que puedan entregar lo que se requiere. Se les puede solicitar que verifiquen la precisión de los materiales escritos finales y sugieran enmiendas de una manera útil y constructiva. Antes de que comience la producción, el Audiovisual Production Researcher debe identificar, negociar los honorarios y concluir las autorizaciones de derechos de autor. Debe identificar las cuestiones legales relacionadas con todos los materiales utilizados en las tomas, incluidos los materiales de archivo, la propiedad intelectual o la música.

También se puede solicitar a los Audiovisual Production Researcher que preparen materiales de producción para uso externo, incluidas hojas informativas, libros y folletos para acompañar las producciones y material publicitario como facturas de producción, comunicados de prensa, sitios web relacionados y páginas de texto.

Vivat Academia. Revista de Comunicación. 15 diciembre 2020 /15 marzo 2021, nº 153, 55-71 
Hernández Alfonso, E. A., Paz Enrique, L. E. y Pérez Cabrera, R. M.

El rol del audiovisual production researcher en el tratamiento de la documentación audiovisual

El Audiovisual Production Researcher constituye, por tanto, una superación de los roles mencionados con anterioridad. Es un profesional que puede integrar las funciones del Production Researcher, TV Researcher y Film Researcher.

\section{REFERENCIAS}

Bailac, M. \& Català, M. (2003). El documentalista audiovisual. El profesional de la información, 12(6), 486-488. http:/ / www.elprofesionaldelainformacion.com/contenidos/2003/noviembre/12. $\underline{\mathrm{pdf}}$

Caldera, J. (2003). La documentación audiovisual en las empresas televisivas. Biblios, 4(15), 3-11. https://dialnet.unirioja.es/ejemplar/81198

Caldera, J. (2015). Production Research: el nuevo rol profesional para nuevos tiempos en la gestión de la información audiovisual. Investigación Bibliotecológica, 29(66), 7989. https:/ / www.sciencedirect.com/science/article/pii/S0187358X16000277

Caldera, J. \& Arranz, P. (2013). Documentación audiovisual en televisión. Revista Española de Documentación Científica, 4(36), 1-2. http://redc.revistas.csic.es/index.php/redc/article/view/828/1043

Caldera, J. \& Freire, R. O. (2016). Los metadatos asociados a la información audiovisual televisiva por "agentes externos" al servicio de documentación:

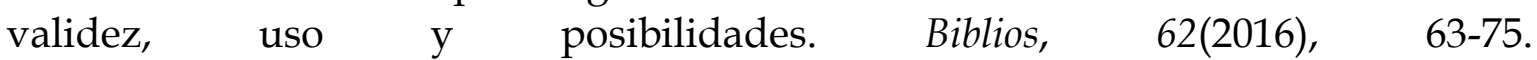
https://biblios.pitt.edu/ojs/index.php/biblios/article/view/285/254

Caldera, J. \& León, J. A. (2010). Análisis de la comercialización de los archivos audiovisuales televisivos por la red: posibilidades e implicaciones. Investigación Bibliotecológica, 24(52), 217-235. $\quad \underline{\text { htp://rev- }}$ ib.unam.mx/ib/index.php/ib/article/view/27461/25450

Caldera, J. \& Nuño, M. V. (2002). Etapas del tratamiento documental de imagen en movimiento para televisión. Revista General de Información y Documentación, 12(2), 375-392.

https://revistas.ucm.es/index.php/RGID/article/view/RGID0202220375A/1009 $\underline{2}$

Cano, E. (2015). ¿Qué es un documentalista? Recuperado de http://enriquecano.es/blog/que-es-un-documentalista. Consultado el 15/11/ 2017.

Cebrián, M. (1995). Información audiovisual: Concepto, técnica, expresión y aplicaciones. España: Editorial Síntesis, S.A. 
Hernández Alfonso, E. A., Paz Enrique, L. E. y Pérez Cabrera, R. M.

El rol del audiovisual production researcher en el tratamiento de la documentación audiovisual

Cuadra, E. (2007). Documentación audiovisual. DVI: Un nuevo documento. Ponencia presentada en el Quintas Jornadas: I. Imagen y documentación, Madrid.

Cuadra, E. (2013). Documentación cinematográfica. Barcelona: Editorial UOC, 2013.

Dokumentalistas. (2016) ¿Qué es y cómo convertirse en Documentalista Audiovisual? Recuperado de https://papelesdemusica.wordpress.com/2011/03/10/blog$\% \mathrm{C} 2 \% \mathrm{BFque}$-es-y-como-convertirse-en-documentalista-audiovisual/ Consultado el 1/11/2017.

Hernández, E. A., Martínez, Y. \& Paz, L. E. (2017). Roles en el procesamiento de documentos audiovisuales en televisiones locales. Razón y Palabra, 21(2-97), 541551. https:// www.revistarazonypalabra.org/index.php/ryp/article/view/894

Herrera, R. (2013). ¿Estamos "infoxicados"? ¿Quién nos "desinfoxicará"? GIGA 3(3), 38-41.

https://www.copextel.com.cu/sites/default/files/revistas/GiGA-32013.pdf

Hidalgo, P. (1999). Análisis documental de audiovisuales. En Introducción a la documentación informativa y periodística. Madrid: Sevilla: MAD.

Hidalgo, P. (2003). La selección de documentos audiovisuales en televisión: la selección en TVE. Documentación de las Ciencias de la Información, 26(2003), 233-260. https://revistas.ucm.es/index.php/DCIN/article/view/DCIN0303110233A/1937 $\underline{3}$

López, I. (2013). Uso de imágenes de archivo en publicidad audiovisual: estudio de casos. El profesional de la información, 23(1), 26-35. http:// www.elprofesionaldelainformacion.com/contenidos/2014/enero/03.pdf

López, A., Sánchez, R. \& Pérez, J. R. (2003). Tratamiento de la documentación audiovisual en el entorno digital: iniciativas de metadatos y lenguajes de descripción multimedia. El profesional de la información, 12(6), 443-451. http:// www.elprofesionaldelainformacion.com/contenidos/2003/noviembre/3.p $\underline{\mathrm{df}}$

López, E. (2014). Rasgos y trayectorias de la documentación audiovisual: logros, retos y quimeras. El profesional de la información, 23(1), 5-12. http:// www.elprofesionaldelainformacion.com/contenidos/2014/enero/01.pdf

Muñoz, P., Meana, S. \& Sáez, S. (2014). Cinco años de experiencia digital en los Servicios Informativos de TVE: una nueva gestión de contenidos. El profesional de la información, 23(1). http:// www.elprofesionaldelainformacion.com/contenidos/2014/enero/09.pdf 
Hernández Alfonso, E. A., Paz Enrique, L. E. y Pérez Cabrera, R. M.

El rol del audiovisual production researcher en el tratamiento de la documentación audiovisual

Pérez, F. (1996). La documentación audiovisual en RTVE. Archivos de la Filmoteca, 1(23-24), 122-133.

Suing, A. (2011). La Televisión Local en Loja - Ecuador. Estudio de las características de servicio, participación y contenidos propios, entre julio y agosto de 2009. Razón y Palabra, 75(2011), 1-28. https://www.redalyc.org/pdf/1995/199518706067.pdf

\section{AUTOR/ES:}

\section{Eduardo Alejandro Hernández Alfonso:}

Licenciado en Comunicación Social. Doctorando de Ciencias Sociológicas. Profesor de la Universidad Central "Marta Abreu" de Las Villas. Ha publicado más de 60 artículos científicos, en su mayoría grupos 1 y 2, los cuales se localizan fundamentalmente en España, Costa Rica, Brasil, Uruguay y Chile. Las principales temáticas de publicación son: investigación en medios de comunicación, estudios comunitarios, diseño visual, estudios métricos de la información, conservación de documentos. Tiene un total de 126 citas y un Índice H de 7.

ealejandro@uclv.cu

\section{Índice $\mathrm{H}$ : 7}

Orcid ID: https:// orcid.org/0000-0002-6446-1653

Google Scholar: https:// scholar.google.com/citations?user=G1a38dEAAAAJ\&hl=es

\section{Luis Ernesto Paz Enrique:}

Licenciado en Ciencias de la Información. Doctorando de Ciencias Sociológicas. Profesor de la Universidad Central "Marta Abreu" de Las Villas. Ha publicado más de 60 artículos científicos, en su mayoría grupos 1 y 2, los cuales se localizan fundamentalmente en Costa Rica, España, Brasil, Uruguay y Chile. Las principales temáticas de publicación son: evaluación de la ciencia y la actividad científica, estudios métricos de la información, políticas sobre ciencia y tecnología, conservación del patrimonio bibliográfico documental, diseño de servicios y arquitectura de información. Tiene un total de 122 citas y un Índice H de 7.

luisernestope@uclv.cu

\section{Índice $\mathrm{H}: 7$}

Orcid ID: https:/ / orcid.org/0000-0001-9214-3057

Google Scholar: https:// scholar.google.com/citations?user=KI8x5s0AAAAJ\&hl=es

\section{Rachel Milagros Pérez Cabrera:}

Licenciada en Ciencias de la Información. Especialista de servicios de información del Centro de Recursos de Aprendizaje. Universidad de Cienfuegos "Carlos Rafael Rodríguez".

rpcabrera@nauta.cu 